\section{Professor Dr. Lothar Jäger zum 75. Geburtstag}

Am 13. Februar 2009 wurde Prof. Dr. med. Lothar Jäger 75 Jahre alt. Deutschlands Allergologen gratulieren einem integren Arzt und Wissenschaftler mit großer Vorbildwirkung auf seine Schüler und wünschen vor allem Gesundheit!

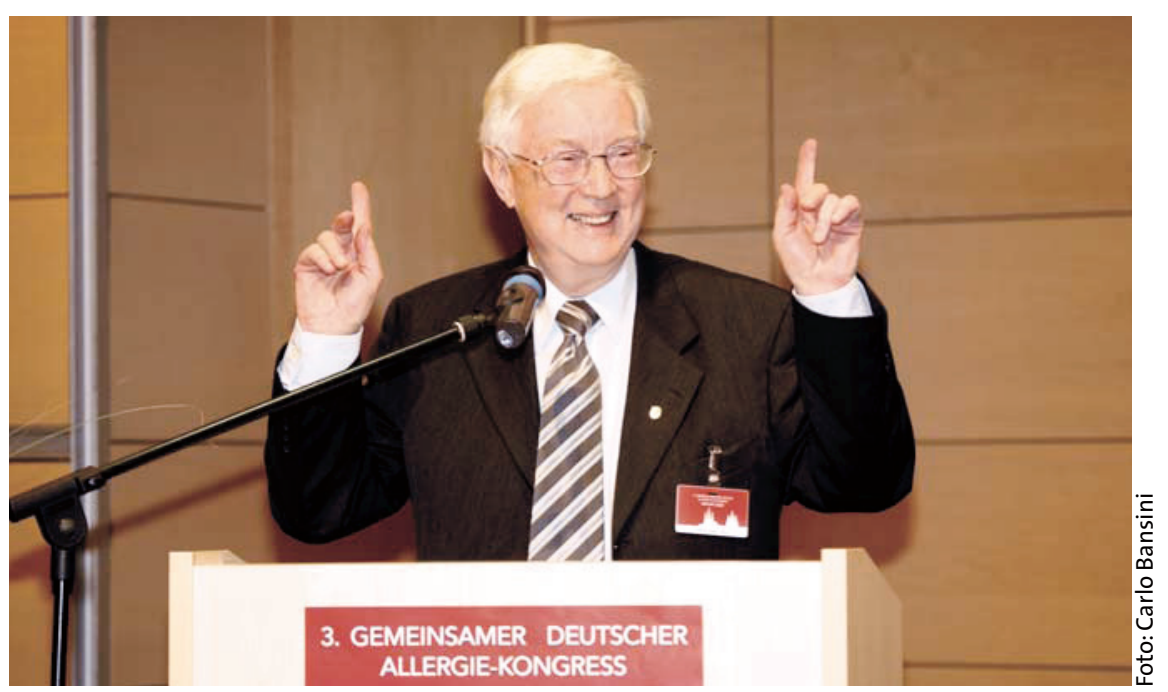

Es geht aufwärts - Prof. Dr. Lothar Jäger am Rednerpult beim 3. Gemeinsamen Deutschen Allergiekongress in Erfurt im September 2008

$\mathrm{N}$ ach dem Studium der Humanmedizin von 1951 bis 1956 folgte für Professor Jäger eine steile akademische Karriere: Bereits als 33-Jähriger habilitierte er sich und mit 36 wurde er ordentlichen Professor für Innere Medizin sowie stellvertretender Direktor der Medizinischen Universitätspoliklinik der Friedrich-Schiller-Universität, Jena.

\section{Erstes Institut für Immunologie}

Es ist Professor Jäger zu verdanken, dass das erste Institut für klinische Immunologie der ehemaligen DDR und eines der ersten in Deutschland überhaupt in Jena an der Friedrich-Schiller-Universität gegründet wurde. Das Jenenser Institut mit klinischem Bereich und Labor entwickelte sich unter der Leitung des Jubilars zu einer angesehenen Forschungs-, Ausbildungs- und Lehrstätte für Wissenschaftler, Ärzte und Studenten aus dem In- und Ausland. Weltweit beachtete Ergebnisse auf dem Gebiet der Ätiologie und Pathogenese allergischer Erkrankungen, der
Mechanismen der Desensibilisierung, der Allergenanalyse, der Pathogenese von Autoimmunerkrankungen und von Immundefekten wurden erarbeitet, die in unzähligen Büchern, Publikationen, Dissertationen und Habilitationen ihren Niederschlag fanden. Unterstützung und Förderung in seinen Vorhaben erfuhr er in dieser Zeit vom Nestor der deutschen Allergologie, Prof. Dr. med. Erich Fuchs, über die innerdeutsche Grenze hinweg.

\section{Seit zehn Jahren im „Unruhestand“}

Professor Jäger war in zahlreichen bedeutenden nationalen und internationalen Gremien und Gesellschaften für die allergologisch-immunologische Wissenschaft und Lehre tätig und als Ratgeber gefragt. In sieben Redaktionsgremien allergologischer und pneumologischer Zeitschriften arbeitete er mit. Auch nach seiner Emeritierung 1999 war Professor Jäger weiter wissenschaftlich tätig. Von 1999 bis 2003 leitete er die klinische Forschung der Allergopharma J. Ganzer KG,
Reinbek. Eigentlich schon lange im Ruhestand angekommen, war er erst im September 2008 Ehrenpräsident des 3. Gemeinsamen Deutschen Allergiekongresses in Erfurt und gestaltete aktiv die Tagung mit. Unter den vielen Auszeichnungen seien nur der Dr.-Karl-HeyerPreis 1996, die Ernst-von-Bergmann Plakette 1998 und die Viktor-RuppertMedaille 1999 erwähnt.

Als Hochschullehrer sorgte Jäger für ein wissenschaftlich strenges, aber tolerantes Arbeitsklima. Seine ehemaligen Schüler verehren ihn für sein Verantwortungsgefühl für die Mitarbeiter und für sein Vorbild als kompetenter, menschlicher Arzt und begabter Forscher. Nicht wenige der "Jäger-Schüler" sind heute als Institutsleiter, Chefärzte, Oberärzte, Wissenschaftler oder als engagierte Ärzte in der Praxis tätig.

\section{Vision: Facharzt für Allergologie}

Nach der Wiedervereinigung warb Professor Jäger, Zukunft voraussehend, für die deutschlandweite Einführung des Facharztes für Allergologie und klinische Immunologie nach Schweizer Vorbild. Die Erfüllung dieser Vision gelang bisher nicht. Die Allergologen Deutschlands sollten jedoch in Anbetracht der steigenden Unterversorgung Allergiekranker durch die politische gewollte Banalisierung ihrer Leiden, die zur Selbstfinanzierung von Medikamenten durch die $\mathrm{Pa}$ tienten und mit dem EBM 2009 zu drastischen Honorarabflüssen bei den allergologisch tätigen Ärzten führt, einen erneuten Vorstoß wagen.

Priv.-Doz. Dr. Kirsten Jung, Erfurt

Impressum "Der ÅDA informiert"

Verantwortlich für den Inhalt

Prof. Dr. Ludger Klimek, Wiesbaden

Redaktion

Markus Seidl

Verlag

๑) Urban \& Vogel GmbH, München

ÄDA-Geschäftsstelle

Service Systems, Dreieich

Tel.: (o 6103 ) 62273

Fax: (o 61 03) 697019

E-Mail:info@aeda.de

Internet: www.aeda.de 